\title{
Chemical burns acid or alkali, what's the difference?
}

\author{
Dalia G. Said ${ }^{1} \cdot$ Harminder S. Dua $\mathbb{D}^{1}$
}

Received: 9 September 2019 / Accepted: 9 September 2019 / Published online: 17 December 2019

(c) The Royal College of Ophthalmologists 2019

Acids, alkalis and alcohols are the commonest chemical agents involved in injuries to the eye and the individual. Chemical injuries assume special significance when the eyes are involved as the effect can lead to profound sight loss despite timely and aggressive management. Chemical injury represents up to $22 \%$ of ocular trauma. It is more common in men with outdoor or industrial occupation although in the recent years assault and hate crimes have been implicated to the increased rate of chemical burns, which in the recent years have amounted up to $33 \%$ of severe ocular burns [1,2].

Alcohol causes the least injury with mainly deepithelialization of the ocular surface, which heal with no further consequences.

Acid and alkali injuries have traditionally been assigned clearly defined pathophysiological pathways by which injury and tissue damage occurs but in severe cases the outcome is equally devastating. Acids usually causes tissue coagulation and shrinking of collagen fibres. Ocular surface tissue proteins bind to acid molecules neutralizing the acid and causing coagulative necrosis. The coagulum acts as a barrier preventing further penetration of the acid, theoretically limiting its damaging effect [1].

Alkali burns that represent two third of chemical burns worldwide, cause hydrophilic and lipophilic degeneration. Saponification of the fatty acids of cell membrane causes rapid penetration of the alkali into the cells. With hydrolysis of the interfibrillar glycosaminoglycans and shrinking of the collagen fibrils, the tissue becomes more susceptible to enzymatic degradation with further penetration of the alkali into the ocular tissue [1].

Dalia G. Said

daliagsaid@gmail.com

1 Department of Ophthalmology, Section of Academic Ophthalmology, Division of Clinical Neuroscience, University of Nottingham, Nottingham, UK
It is almost customary to check the $\mathrm{pH}$ of the eye as soon as a patient with ocular chemical injury attends the eye emergency department, to ascertain whether the injurious agent was an acid or an alkali. It is important to emphasize that the first step should be to ascertain whether the patient has ingested or inhaled the noxious agent and whether there is risk of asphyxiation from oedema of the respiratory passage or internal damage by ingestion. Evaluation of vital signs and history from the patient or escorts is important in this regard. Call for help from the 'crash team' may be required.

Assessment of $\mathrm{pH}$ with the litmus paper is a crude but practical means of ascertaining whether the agent was an acid or alkali, but more so to know whether it is normal or not, and to serve as a baseline from which a change can be measured. Copious irrigation of the open eye(s), preferably with a sterile neutral solution, is the essential immediate measure, regardless of the nature of the chemical. Use of topical anaesthesia to relieve pain and to release blepharospasm is often essential (copious irrigation over eyelids squeezed shut is known to occur). After initial irrigation, which can be done with balanced salt solution, or any other available solutions such as water, saline, phosphate buffered saline, ringer lactate or Diphoterin ${ }^{\circledR}$, irrigation is stopped, $\mathrm{pH}$ is checked and irrigation re-instituted if the $\mathrm{pH}$ is not neutral. If $\mathrm{pH}$ is neutral, it is important to re-check after a pause of a few minutes as chemicals from the tissue can leech out indicating that more irrigation is needed. Of all the irrigating agents mentioned, Diphoterin ${ }^{\circledR}$, which is a hypertonic, amphoteric chelating agent that helps wash the chemicals with additional neutralisation and chelation action and prevents further tissue penetration of the chemicals has proven to be more effective with smaller quantities required to achieve neutralization of the chemical agent [3]. Any visible particulate matter in the conjunctival sac and fornices, examined by double eversion where possible, whether lying on the surface or impregnated in the tissue should be removed or excised.

In this issue of the Journal, Monaghan et al. [4] have studied the reliability of the litmus paper in yielding accurate $\mathrm{pH}$ measurements. They make a valid point that the 
litmus strips are often light exposed, degraded and can give inaccurate measurements of $\mathrm{pH}$. However, they recorded good correlation in $\mathrm{pH}$ measurements showing that only $5 \%$ of the readings were unreliable. This can be addressed by ensuring a fresh supply of strips are available and stored at the right temperature in coloured glass containers. Accuracy of the $\mathrm{pH}$ measurement is not absolutely critical for the management decision, especially if it is measured again, after a few minutes of cessation of irrigation and the process repeated until there is no further change in $\mathrm{pH}$.

The overall acute stage management of chemical burns involves (a) Prevention of further damage by elimination as much of the injurious agent as possible, (b) complete and thorough assessment, (c) control for the acute inflammatory reaction, (d) facilitation of the healing process and (e) prevention and management of complications [5]. Irrigation is the first and important step in preventing further damage and eliminating the injurious agent. Complete and thorough assessment includes systematic examination of every structure of the eye, use of fluorescein stain and classification of the burn. Two prognostic classifications are in vogue, the Roper-Hall and the Dua's classification [6, 7]. The latter has been shown to be more reliable in determining prognosis of the injury [8]. It is imperative to assess the intraocular pressure using finger palpation if other means are unreliable or not practical. Control of inflammation involves the judicious use of steroids, antiproteases like tetracycline, sodium citrate (10\%) and application of amniotic membrane $[9,10]$. Oral ascorbate (topical is extremely irritant) up to $2 \mathrm{~g} /$ day is important to replenish the depleted aqueous ascorbate levels. Autologous serum drops help in epithelial healing [10]. Surgical intervention in the form of tenoplasty and autologous conjunctival grafts from the other eye are important in cases of limbal ischemia [11]. Finally, antibiotic cover, use of non-adrenergic mydriatics (cause vasoconstriction and aggravate ischaemia) and antiglaucoma medication if necessary are important in prevention and management of complications. A host of ocular surface reconstructive measures come into play in the late stage of chemical burns, of which limbal stem cell transplantation and the current availability of HOLOCLAR, approved by NICE for unilateral chemical burns are key interventions [12].

\section{Compliance with ethical standards}

Conflict of interest DGS: consultant for Santen, Chiesi, Dompe. HSD: consultant for Santen, Chiesi, Thea, Dompe. Shareholder in NuVision.

Publisher's note Springer Nature remains neutral with regard to jurisdictional claims in published maps and institutional affiliations.

\section{References}

1. Wagoner M. Chemical injuries of the eye: Current concepts in pathophysiology and therapy. Surv Ophthalmol. 1997;41: 275-313.

2. Macdonald E, Cauchi P, Azuara-Blanco A, Foot B. Surveillance of severe chemical corneal injuries in the UK. Br J Ophthalmol. 2009;93:1177-80.

3. Lynn D, Zukin L, Dellavalle R. The safety and efficacy of Diphoterine for ocular and cutaneous burns in humans. Cutan Ocul Toxicol. 2017;36:185-92.

4. Monaghan MT, Brogan K, Lockington D, Rotchford A, Ramaesh K. Variability in measuring $\mathrm{pH}$ using litmus paper and the relevance in ocular chemical injury. Eye. 2019. https://doi.org/ 10.1038/s41433-019-0737-z.

5. Sharma N, Kaur M, Agarwal T, Sangwan V, Vajpayee R. Treatment of acute ocular chemical burns. Surv Ophthalmol. 2018;63:214-35.

6. Roper-Hall MJ. Thermal and chemical burns. Trans Ophthalmol Soc UK. 1965;85:631-53.

7. Dua H. A new classification of ocular surface burns. Br J Ophthalmol. 2001;85:1379-83.

8. Gupta N, Kalaivani M, Tandon R. Comparison of prognostic value of Roper Hall and Dua classification systems in acute ocular burns. Br J Ophthalmol. 2010;95:194-8.

9. Burns FR, Stack MS, Gray RD, Paterson CA. Inhibition of purified collagenase from alkali-burned rabbit corneas. IInvest Ophthalmol Vis Sci. 1989;30:1569-75.

10. Baradaran-Rafii A, Eslani M, Haq Z, Shirzadeh E, Huvard M, Djalilian A. Current and upcoming therapies for ocular surface chemical injuries. Ocul Surf. 2017;15:48-64.

11. Dua H, Miri A, Faraj L, Said D. Free autologous conjunctival grafts. Ophthalmology. 2012;119:2189-2189.e2.

12. Pellegrini G, Ardigò D, Milazzo G, Iotti G, Guatelli P, Pelosi D, et al. Navigating market authorization: the path holoclar took to become the first stem cell product approved in the European union. Stem Cells Transl Med. 2017;7:146-154. 